\title{
Neutrophils to lymphocytes and platelets to lymphocytes ratios in patients with chronic hepatitis B virus
}

\author{
Gamal E Shiha ${ }^{1}$, EL-Shahat Toson ${ }^{2}$ and Ryham M EL-Sawah ${ }^{* 2}$ \\ ${ }^{1}$ Department of Internal Medicine, Faculty of Medicine, Mansoura University and Egyptian Liver Hospital. \\ ${ }^{2}$ Chemistry Department, Faculty of Science, Damietta University, New Damietta City, Egypt.
}

Received: 22 August 2020 /Accepted: 2 December 2020

* Corresponding author’s E-mail: reham.magdy.sawah@gmail.com

\begin{abstract}
Systemic liver inflammation occurs as the result of liver injury. This can be cause by hepatitis B virus (HBV) infection. Whether neutrophils to lymphocytes ratio (NLR) and platelets to lymphocytes ratio (PLR) are capable to be included as systemic inflammatory markers or not will be investigated. Their correlations with liver function tests and with viral DNA were also tested in patients with chronic hepatitis B (CHB).Patients and Methods: Blood sample were taken from patients $(n=42)$ and from the healthy control $(n=20)$.HBV-DNA, hepatitis B surface antigen (HBsAg), total white blood cells count as well as neutrophils, lymphocytes and platelets were done for each individual. Also, liver function tests were estimated. Results: The platelets counts in the blood of patients was significantly decreased when compared with that of the healthy control $(\mathrm{P}<0.002)$. The percentage of neutrophil was also decreased in patients when compare with the control value. Such percent was not significant $(\mathrm{P}<0.837)$. Further, the percentage of lymphocyte was not significantly increased in the blood of patients when compare with the healthy control value $(\mathrm{P}<0.72)$. Taken together, the NLR and PLR were decreased in patients when compare with the healthy control values but such decreases were not significant ( $\mathrm{P}<0.89$ and 0.28 , respectively). PLR was significantly and positively correlated with ALT and viral DNA ( $\mathrm{P}<0.02, \mathrm{P}<0.04$, respectively). Conclusion: NLR and PLR, as systemic inflammatory markers cannot be used as indicators for the presence of liver inflammation in chronic hepatitis B (CHB) patients. In spite, such chronicity can only reduce platelets and lymphocytic counts.
\end{abstract}

Keywords: HBV. HBV-DNA, NLR, PLR.

\section{Introduction}

Hepatic injury is a pathophysiological process that occurs when blood flow and oxygen delivery are restored after hypoxia, leading to increased organ damage. Hepatocyte damage can occur during both the ischemic and reperfusion phases.
The end result is cellular death through a combination of apoptosis and necrosis. It has been established that the length and method of ischemia applied to the liver and the background liver condition determine the degree of Liver injury that is sustained [1].

Activation of systemic inflammation is characterized by an excessively proinflammatory cytokine profile which is believed to mediate 
hepatic inflammation, apoptosis, and necrosis of hepatocytes. Hepatocyte necrosis may trigger a complicated immune response that includes the emigration of granulocytes from the bone marrow into the peripheral blood. Additionally, an excessive immune activation may result in a reduction of lymphocytes numbers caused by impaired lymphopoiesis and cell necrosis [2]. Neutrophils-to-lymphocytes ratio (NLR) and platelets-to-lymphocytes ratio (PLR) are novel inflammatory biomarkers used as prognostic factors in various diseases. They can be easily calculated and are widely available but they may be affected by several inflammatory conditions. NLR has recently emerged as a new important inflammatory marker for predicting cardiovascular events, insulin resistance (IR), and atherosclerotic plaques. The PLR has been considered as inflammatory marker that can predict thrombotic events and severe atherosclerosis $[3,4,5,6]$. In the present study, NLR and PLR were calculated. Their correlations with liver function tests were also done.

\section{Patients and methods:}

\section{Patient selection}

We recruited 63 participants in the present study, 41 patients with chronic hepatitis B and 21 healthy controls. Their age range was from 21 to 65 years for both male and female subjects. They were enrolled from Egyptian liver hospital, Sherbin, Dakahlia, Egypt.

\section{Blood sampling}

Blood samples were obtained from all participants. Four milliliters of blood were drawn from the antecubital vein in each case on EDTA.

\section{Methods}

\section{Haematological parameters}

Complete blood counts including white blood cell count (WBC), platelet (PLT) neutrophil count, lymphocyte count, monocyte count, and other parameters were analyzed using D-cell 60 automated Hematology analyzer (D-cell60; Diagon ltd, Budapest, Hungary).
Neutrophils to Lymphocyte Ratio (NLR)

NLR was calculated by dividing the percentage of neutrophils on lymphocyte.

\section{Platelets to Lymphocyte Ratio (PLR)}

PLR was calculated by dividing the count of platelets on that of lymphocytes.

\section{Routine Liver function tests}

Activities of alanine amino-transferase (ALT) and aspartate amino transferase (AST), albumin (ALB) and total bilirubin levels were measured by using kits provided by Biomed Egy-chem for lab technology company, Cairo, Egypt.

\section{Virological assessments}

Serum HBV DNA load was determined by realtime PCR, using reagent kit provided by COBAS ${ }^{\circ}$ TaqMan ${ }^{\circledR} H B V$ test, CAP-CTM (Roche Molecular Systems, Inc., Branchburg, NJ). HBsAg were measured by enzyme-linked immunosorbent assay (ELISA).

\section{Results}

White blood cells (WBCs):

The mean count of WBCs in healthy control was $7.6 \pm 2.41 \mathrm{cmm} / \mathrm{L}$ and this value in the blood of CHB patients was $6.11 \pm 1.7 \mathrm{cmm} / \mathrm{L}$. The difference between these two mean values was statistically significant $(\mathrm{P}<0.008$, table 1$)$.

\section{Platelets:}

The mean platelets count in the blood of the healthy control was $242.8 \pm 45.27 \mathrm{cmm} / \mathrm{L}$ and this value in the blood of CHB patients was $194.27 \pm 63.16 \mathrm{cmm} / \mathrm{L}$. The decreases in these two mean values was statistically significant $(\mathrm{P}=0.002$, Table 1).

\section{Lymphocytes:}

The mean lymphocytic count in the blood of the healthy control was $251.7 \pm 62.2$ and this value in

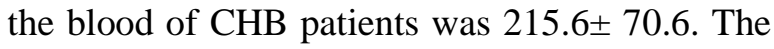
decreases in these two mean values was statistically significant $(\mathrm{P}<0.02$, Table 1$)$. 


\section{Neutrophils (\%):}

In healthy control, the mean count of neutrophils percentage was $52.98 \pm 9.32 \%$ and this value in the blood of CHB patients was $52.75 \pm 10.50 \%$. The difference in these two mean values was statistically not significant $(\mathrm{P}=0.837$, Table 1$)$.

\section{Lymphocytes (\%):}

In healthy control, the mean percentage of lymphocytes was $34.24 \pm 8.81 \%$ and this value in the blood of CHB patients was $35.54 \pm 8.60 \%$. The difference in these two mean values was statistically not significant $(\mathrm{P}=0.724$, Table 1$)$.
Neutrophils to Lymphocyte Ratio:

In healthy control, the mean value of neutrophils to lymphocyte ratio was $1.72 \pm 0.730$. This value in the blood of CHB patients was $1.61 \pm 0.56$. The difference in these two mean values was statistically not significant $(\mathrm{P}=0.899$, Table 1$)$.

\section{Platelets to Lymphocyte Ratio:}

In the blood of the healthy control, the mean value of platelets to lymphocyte ratio was $1.04 \pm 0.38$. This value in the blood of CHB patients was $0.92 \pm 0.32$.The difference in these two mean values was statistically not significant $(\mathrm{P}=0.285$, Table 1).

Table 1: Hematological parameters investigations of the studied groups .

\begin{tabular}{llllll}
\hline \multicolumn{1}{c}{ Parameters } & \multicolumn{3}{c}{ Controls } & \multicolumn{1}{c}{ Patients } & P value \\
\cline { 2 - 4 } WBCs count $\left(10^{3} / \mu \mathrm{L}\right)$ & $\mathrm{N}$ & \multicolumn{1}{c}{ Mean $\pm \mathrm{SD}$} & $\mathrm{N}$ & $\mathrm{Mean} \pm \mathrm{SD}$ & $\mathrm{P}<0.008$ \\
Platelets $\left(10^{3} / \mu \mathrm{L}\right)$ & 20 & $7.6 \pm 2.41$ & 39 & $6.11 \pm 1.7$ & $\mathrm{P}<0.002$ \\
Lymphocyte count & 20 & $242.8 \pm 45.27$ & 37 & $194.27 \pm 63.16$ & $\mathrm{P}<0.02$ \\
Neutrophils $(\%)$ & 20 & $251.7 \pm 62.2$ & 39 & $215.6 \pm 70.67$ & $\mathrm{P}<0.837$ \\
Lymphocyte $(\%)$ & 20 & $52.98 \pm 9.32$ & 38 & $52.75 \pm 10.50$ & $\mathrm{P}<0.724$ \\
NLR & 20 & $34.24 \pm 8.81$ & 39 & $35.54 \pm 8.60$ & $\mathrm{P}<0.899$ \\
PLR & 20 & $1.72 \pm 0.7301$ & 38 & $1.61 \pm 0.56$ & $\mathrm{p}<0.285$ \\
\hline
\end{tabular}

$\mathrm{WBC}=$ White blood cells, NLR $=$ neutrophils to lymphocytes ratio, $\mathrm{PLR}=$ platelets to lymphocytes ratio, values were expressed as Mean \pm Standard deviation $(\mathrm{SD})$ and $\mathrm{P}=$ Probability that was significant when $(\mathrm{P}<$ $0.02)$, extremely significant when $(\mathrm{P}<0.0001)$ and non-significant when $(\mathrm{P}>0.05)$.

Correlations between neutrophils to lymphocytes ratio (NLR) and the parameters of liver functions tests:

Table 2 showed that NLR had negative but not significant correlation with albumin. With ALT, AST and total bilirubin, the positive correlations were not significant (figure 1).

Table 2: Correlations between neutrophils to lymphocyte ratio with the parameters of liver functions tests.

\begin{tabular}{lllll}
\hline $\begin{array}{l}\text { Parameter } \\
\mathbf{S}\end{array}$ & $\begin{array}{l}\text { Albumi } \\
\mathbf{n}\end{array}$ & ALT & AST & $\begin{array}{l}\text { Total } \\
\text { bilirubi } \\
\mathbf{n}\end{array}$ \\
\hline $\mathrm{NLR}$ & & & & \\
$\mathrm{R}$ & $0.222-$ & 0.000 & 0.06 & 0.15 \\
& & 1 & 6 & \\
$\mathrm{P}$ & 0.09 & 0.9 & 0.6 & 0.23 \\
$\mathrm{~N}$ & 58 & 58 & 58 & 58 \\
\hline $\mathrm{N}=$ Number & of & individuals, & R=Pearson \\
Correlation & coefficient P=Probability, NLR=
\end{tabular}

neutrophils to lymphocytes ratio, ALT=Alanine aminotransferase and AST $=$ Aspartate aminotransferase.
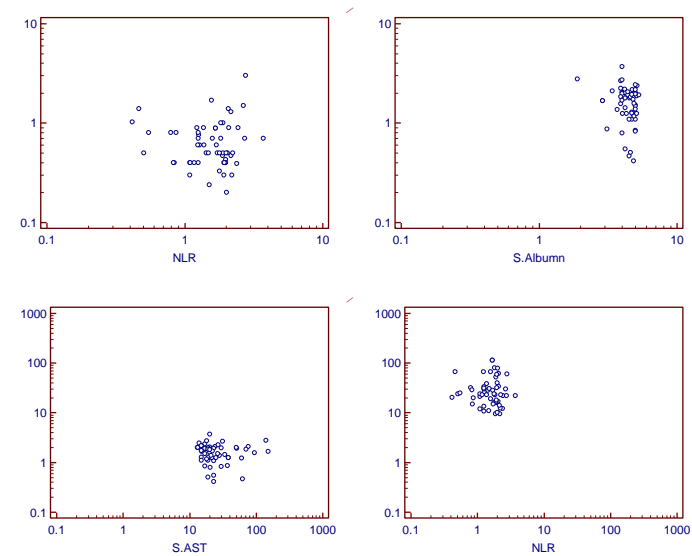

Figure 1: Correlations of NLR with albumin and total bilirubin as well as ALT and AST activities.

Correlations between platelets to lymphocyte ratio $(P L R)$ with the parameters of liver functions tests:

Table 3 showed that PLR had positive correlation with albumin $(\mathrm{P}<0.3)$, negative and significant correlation with ALT $(\mathrm{P}<0.02)$ and negative but not significant correlation with AST and total bilirubin $(\mathbf{P}<\mathbf{0 . 3}$ and $\mathbf{P}<\mathbf{0 . 8 7}$, 


\section{respectively, Figure 2).}

Table 3: Correlations between platelets to lymphocyte ratio and with the parameters of liver functions tests.

\begin{tabular}{ccccc}
\hline Parameters & Albumin & ALT & AST & $\begin{array}{c}\text { Total } \\
\text { bilirubin }\end{array}$ \\
\hline PLR & & & & \\
R & 0.11 & $0.29-$ & $0.13-$ & $0.02-$ \\
P & 0.3 & 0.02 & 0.3 & 0.87 \\
N & 57 & 57 & 57 & 57 \\
\hline
\end{tabular}

$\mathrm{N}=$ Number of individuals, $\mathrm{R}=$ Pearson correlation coefficient, $\mathrm{P}=$ Probability, $\mathrm{PLR}=$ platelets to lymphocytes ratio, ALT=Alanine aminotransferase and AST $=$ Aspartate aminotransferase.
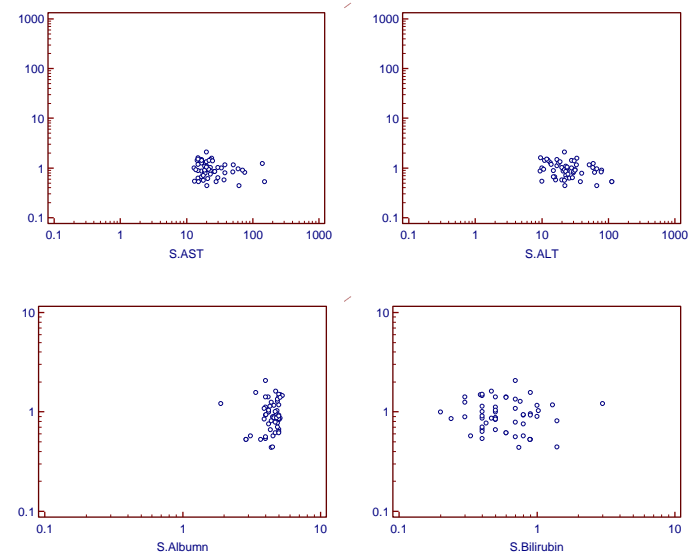

Figure 2: Correlations of PLR with AST and ALT activities as well as total bilirubin and albumin levels.

\section{Correlation between viral load using PCR with NLR and PLR}

As shown in table 3, viral load had positive correlation with NLR and PLR. Its correlation with PLR was significant $(\mathrm{p}<0.04)$.

Table 4: Correlation between viral load using PCR with NLR and PLR:

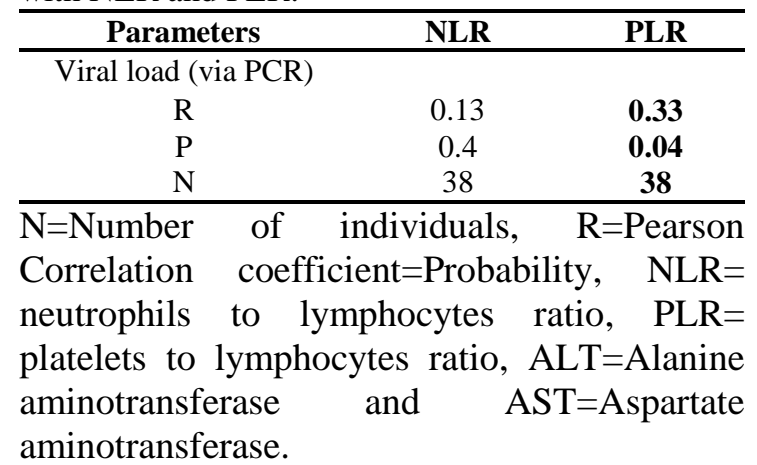

\section{Discussion:}

Systemic inflammatory responses (SIRS) occur frequently in patients with liver failure and were not only correlated with the severity of liver disease but also with its prognosis [7].The PLR and NLR were considered as systemic inflammatory biomarkers and/or immune response-related indicators. It has been also confirmed that, these ratios are related to the progression and prognosis of cardiovascular disorders and thrombotic events [3, 8]. Chronic inflammation, endothelial dysfunction, and direct invasion of the arterial wall have also been cited as possible mechanisms. As the carrier medium, role of platelets for immune effector cells is being clarified [9].The PLR shows the variation in both platelets and lymphocytes. Further, NLR shows the variation in both neutrophils and lymphocytes. They comprehensively indicate an immune status change during the disease period [10].

In the present study, the mean counts of white blood cells, platelets and lymphocyte were significantly decreased when the patients values were compare with those of the healthy control $(p<0.0082, p<0.002$ and $p<0.02$, respectively). These results indicate an immune system involvement during HBV chronicity.

Thrombocytopenia is a common feature of chronic liver disease and has been reported in $49-64 \%$ of cirrhotic patient. Conversely, an increased platelet count has been demonstrated in several malignancies including $\mathrm{HBV}$ infection -related hepatocellular carcinoma (HCC) $[11,12]$. High immature platelet fraction $\%$ (IPF \%) during the course of thrombocytopenia suggests that platelet destruction/sequestration is due to hypersplenism in patients with $\mathrm{CHB}$, which may be the case in the present study [13].

In the present study, the mean counts of white blood cells and lymphocyte were significantly decreased when the patients values were compare with the healthy control $(\mathrm{p}<0.0082$ and $\mathrm{p}<0.02$, respectively). These results indicate an immune system involvement during $\mathrm{HBV}$ chronicity.

Many investigators suggest the chronicity of HBV infection is caused by a deficient cellular immune function, but the mechanism has not been defined. The significant decrease in total $\mathrm{T}$ lymphocyte $\left(\mathrm{CD}^{+} \mathrm{T}\right)$ revealed that there is a lack of immunologically competent cells involved in cellular immunoreactivity against 
HBV infection. Activation-induced cell death (AICD) is related to a decrease in lymphocytes and functional defects. This phenomenon can cause decreased immune clearance. Therefore, the reduction in lymphocytic count may be an important reason for HBV persistence, in the present study.

The study of [14] and [15] clearly showed that, the severity of the liver disease was significantly associated with functional disorder of T-lymphocytes, and the effect was independent of viral load. Hepatocyte damage may also be correlated directly with T-cell failure, rather than through the load copies of viral replication. Wang KX and etal (2003) have suggested that hepatocyte damage is mainly caused by immunological injury through the destruction of virus-infected cells. Therefore, immune elimination of infected cells can lead to the termination of infection when it is efficient or to a persistent necroinflammatory disease when it is not [16]. Destruction of infected cells, however, is not the only mechanism implicated in the elimination of intracellular virus but noncytolytic mechanisms of anti-viral protection is also a case [17].

In spite, the mean percent of neutrophils was non-significantly decreased when compare with the healthy control value $(\mathrm{p}<0.837)$ and lymphocytes percent as well $(\mathrm{p}<0.724)$. Unfortunately, both NLR and PLR showed no significant difference among patients and control.

In spite, PLR showed positive and significant correlation with ALT activity $(\mathrm{p}<0.02)$. Such correlation confirm the role of lymphocytes during CHB infection. Also, PLR had significant correlation with PCR. Further, one must take into his consideration that, WBC, platelets, lymphocyte, and neutrophil counts are all vulnerable to infection to a variety of other clinical diseases and are inclined to great fluctuations [18]. Since the results of Mizukoshi E and etal (2003) revealed that $\mathrm{T}$ lymphocytes failure was significantly associated with viral replication level. The substantial linear dose-response relationship and strong independent predictive effect of HBV DNA, but not other variables, on Tlymphocyte subpopulations suggests the possibility of a causal relationship between them. This is why PLR in the present study had significant correlation with HBV-DNA using PCR technique [19].
Various types of lymphoid cells were shown to support HBV replication, being an important, long-term reservoir of the virus [20]. Thus, viral infection of peripheral blood mononuclear cells (PBMCs) in chronic hepatitis B (CHB) has a profound effect on immune cell function and carcinogenesis leading to lymphocyte proliferative disorders, including mixed cryoglobulinemia and B cell in non-Hodgkin lymphoma [21]. Also, persistence of residual HBV-DNA in PBMCs after therapy in SVR patients not only linked with impairment in the immune responses [22] but also with the risk of progression in liver disease and extra hepatic manifestations of HBV infection [23]. The positive and significant correlation of PLR and viral DNA confirm the involvement of immune system during viral chronicity.

In conclusion: NLR and PLR, as systemic inflammatory marker, cannot be used as indicators for the presence of liver inflammation in chronic hepatitis B (CHB) patients. In spite, such chronicity can only reduce platelets and lymphocytic counts. Also PLR, which is better than NLR, correlate significantly with HBVinfection- related disease progression. Thus, continuous monitoring of PLR, but not NLR, will contribute to disease surveillance in $\mathrm{CHB}$ patients with an increasing tendency in predicting a good virological response.

\section{References}

Ramaiah SK, Jaeschke H. (2007). Role of neutrophils in the pathogenesis of acute inflammatory liver injury. Toxicol Pathol , 35: 757-766.

Fan Z, EnQiang C, Yao DL, et al. (2017). Neutrophil-lymphocyte ratio predicts short term mortality in patients with hepatitis B virus related acute-on-chronic liver failure treated with an antificial liver support system. PLoS One, 12:e0175332.

Corriere T, Di Marca S, Cataudella E, Pulvirenti A, Alaimo S, Stancanelli B, Malatino L. (2018). Neutrophil-to-lymphocyte ratio is a strong predictor of atherosclerotic carotid plaques in older adults. Nutr Metab Cardiovasc Dis, 28:2327.

Park JJ, Jang HJ, Oh IY, Yoon CH, Suh JW, Cho YS et al. (2013). Prognostic value of neutrophil to lymphocyte ratio in patients presenting with ST-elevation myocardial infarction undergoing primary percutaneous coronary intervention. Am 
J Cardiol . 111:636-642.

Yildiz A, Yuksel M, Oylumlu M, Polat N, Akyuz A, Acet $\mathrm{H}$ et al. (2015). The utility of the plateletlymphocyte ratio for predicting no reflow in patients with ST-segment elevation myocardial infarction. Clin Appl Thromb Hemost , 21:223228.

Kim B-J., Cho S-H., Cho K-I., Kim H-S., Heo J-H., Cha T-J. (2016). the combined impact of neutrophil-to-lymphocyte ratio and type 2 diabetic mellitus on significant coronary artery disease and carotid artery atherosclerosis. J Cardiovasc Ultrasound, 24:115-122.

Lou M, Luo P, Tang R, Peng Y, Yu S, Huang W, He L. (2015). Relationship between neutrophillymphocyte ratio and insulin resistance in newly diagnosed type 2 diabetes mellitus patients. BMC Endocrine Disorders , 15:9.

Choudhury A, Kumar M, Sharma BC, et al. (2017). Systemic inflammatory response syndrome in acute-on-chronic liver failure: relevance of 'golden window': a prospective study. J Gastroenterol Hepatol, 32:1989-97.

Yildiz A, Yuksel M, Oylumlu M, Polat N, Akyuz A, Acet $\mathrm{H}$ et al. (2015).The utility of the plateletlymphocyte ratio for predicting no reflow in patients with ST-segment elevation myocardial infarction. Clin Appl Thromb Hemost, 21:223228.

Guidotti LG, Inverso D, Sironi L, Di Lucia P, Fioravanti J, Ganzer L et al.(2015). Immunosurveillance of the liver by intravascular effector CD8 (+) T cells. Cell, 161:486-500.

Gutkowski K, Hartleb M. (2008). Usefulness of noninvasive tools in liver fibrosis assessment. Hepatitis monthly, 8:45-50.

Smith RA, Bosonnet L, Raraty M, Sutton R, Neoptolemos JP, Campbell F, Ghaneh P. (2009).Preoperative platelet-lymphocyte ratio is an independent significant prognostic marker in resected pancreatic ductal adenocarcinoma. Am J Surg, 197(4):466-472?

Dou, J.,Lou, Y., Wu, J., Lu, Y. and Jin, Y. (2014). Thrombocytopenia in patients with hepatitis B virus-related chronic hepatitis: evaluation of the immature platelet fraction. Platel,25(6):399-404.
Khettry U, Anand N, Gordon FD, Jenkins RL, Tahan SR,Loda M, Lewis WD. (2000). Recurrent hepatitis B, hepatitis C, and combined hepatitis $\mathrm{B}$ and $\mathrm{C}$ in liver allografts: a comparative pathologi ical study. Hum Pathol, 31: 101-108.

Wang KX, Peng JL, Wang XF, Tian Y, Wang J, Li CP.(2003). Detection of T lymphocyte subsets and mIL-2R on surface of PBMC in patients with hepatitis B. World J Gastroenterol ,9: 2017-2020.

Glebe D. Recent advances in hepatitis B virus research. (2007). a German point of view . World J Gastroenterol , 13: 8-13

Chen M, Sallberg M, Thung SN, Hughes J, Jones J, Milich DR. (2001). Modeling the T-helper cell response in acute and chronic hepatitis $\mathrm{B}$ virus infection using $\mathrm{T}$-cell receptor transgenic mice . Antiviral Res, 52: 99-11.

Meng X, Wei G, Chang Q, Peng R, Shi G, Zheng P et al. (2016).The platelet-to-lymphocyte ratio, superior to the neutrophil-to lymphocyte ratio, correlates with hepatitis $\mathrm{C}$ virus infection. Int $\mathrm{J}$ Infect Dis , 45:72-77.

Mizukoshi E, Sidney J, Livingston B, Ghany M, Hoofnagle JH, Sette A, Rehermann B.(2004). Cellular immune responses to the hepatitis B virus polymerase. J Immunol ,173: 5863-5871.

D.S. Chabot-Richards, T.I. (2015). GeorgeWhite blood cell counts: reference methodology Clin Lab Med, 35 , pp. 11-24.

Skardasi G, Chen AY, Michalak TI. (2018).Authentic patient-derived hepatitis C virus infects and productively replicates in primary $\mathrm{CD} 4+$ and $\mathrm{CD} 8+\mathrm{T}$ lymphocytes in vitro. J Virol ,92:e01790-17. doi: 10.1128/JVI.01790-17.

Dai B, Chen AY, Corkum CP, et al. (2016). Hepatitis $\mathrm{C}$ virus upregulates $\mathrm{B}$-cell receptor signaling: a novel mechanism for $\mathrm{HCV}$-associated B-cell lymphoproliferative disorders. Oncogene. ,35:2979-2990. doi: 10.1038/onc.2015.364.

Roque-Cuéllar MC, Sánchez B, García-Lozano JR, et al. (2014). Hepatitis $C$ virus-specific cellular immune responses in sustained virological responders with viral persistence in peripheral blood mononuclear cells . Liver Int, 34:e80-e88.
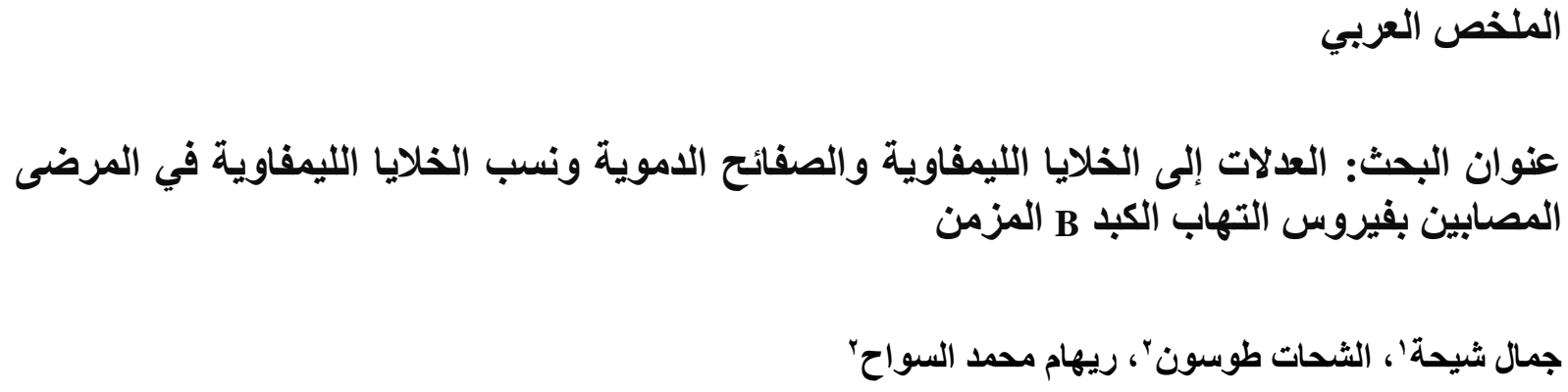


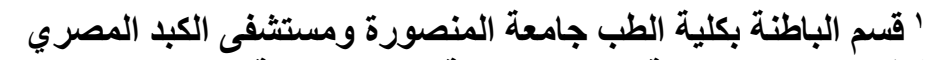

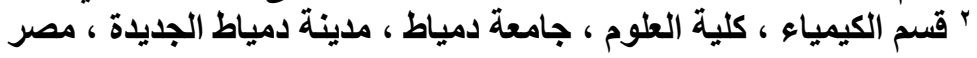

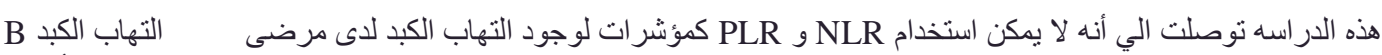

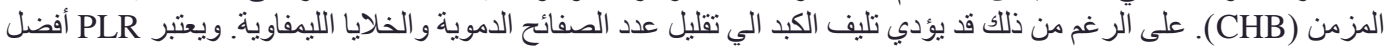

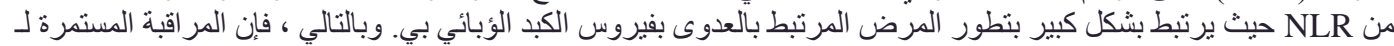

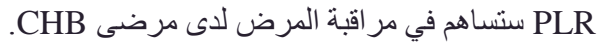

